\title{
The study of mortality variations in small administrative areas of England and Wales, with special reference to cancer
}

\author{
JOAN M. DAVIES AND CLAIR CHILVERS \\ From the Division of Epidemiology, Institute of Cancer Research, Sutton
}

SUMMARY Until recently the basic geographical unit in England and Wales for the compilation of population and mortality data has been the local authority administrative district. Epidemiologists have made little use of the mortality data available from 1950 for small administrative districts: municipal boroughs, urban and rural districts. In April 1974 the boundaries of administrative areas were radically revised, but mortality data for the old districts were still compiled up to 1978 . In this paper we review the material available for small districts and its uses and limitations for research into the causes of cancer. It is argued that these data covering 29 years deserve to be more widely used both for generating clues and for testing hypotheses about the aetiology of cancer and other chronic diseases.

Until recently the counties of England and Wales were divided for the purposes of local government into the divisions shown in the Figure. Mortality data

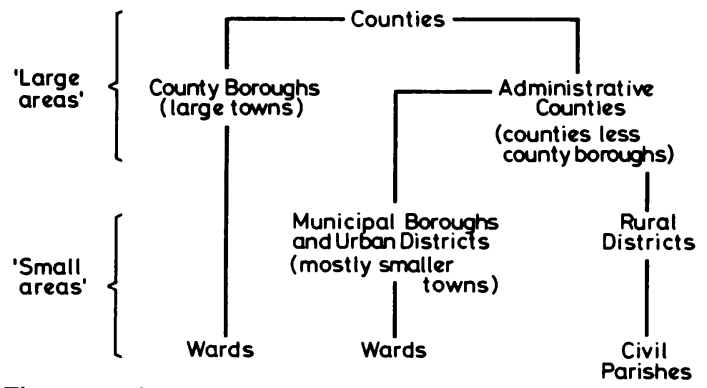

Figure Administrative subdivisions of counties until April 1974.

for counties, county boroughs, and London boroughs in England and Wales have been readily available and extensively used for descriptive purposes, ${ }^{1-4}$ or in the search for associations between death rates and environmental characteristics (for example Gardner, Crawford and Morris ${ }^{5}$ ). However, areas of such large size are unlikely to be homogeneous and hence their usefulness in seeking environmental causes of disease is limited. The study of smaller and more homogeneous areas offers theoretical advantages, although at the same time it presents practical problems.

The purpose of this paper is to describe the data available for small administrative areas, their possible uses for research into the causes of disease, and their inherent limitations. Our main interest is in the use of mortality data for research into the aetiology of cancer, but most of our discussion is equally applicable to other chronic diseases. We are not concerned here with the determination of local priorities for the allocation of medical resources. Small area mortality studies have been carried out in other countries but the problems encountered differ in some respects from those found here; we have accordingly cited studies of mortality only within Great Britain.

The main types of area considered are urban districts (UDs) and rural districts (RDs), referred to collectively as 'districts'. (Municipal boroughs (MBs) are essentially the same for our purposes as UDs and are included under that title). Larger areas are standard regions (aggregates of counties), county boroughs (CBs), London boroughs, and administrative counties (counties less their CBs). We also discuss wards (subdivisions of CBs or UDs), civil parishes (subdivisions of RDs), and enumeration districts (further subdivisions of either of these). 
Districts varied greatly in population size. Relevant census county reports show that in 1971 the populations of UDs ranged from under 2000 to over 70000 persons. RDs had a similarly wide range, and also varied in population density from under $0 \cdot 1$ to over 4.9 persons a hectare.

In April 1974 the local government areas of England and Wales were drastically revised and reduced in number; Greater London remained unchanged, but the 58 counties were reduced to 53 , and 1332 CBs, UDs, and RDs were replaced by 369 'county districts' and 36 'metropolitan districts'. Many former CBs retained virtually unchanged boundaries as county districts but in all cases UDs and/or RDs were combined together, and often individual districts were split up between two or more new county districts. Fortunately mortality data defined by the former district boundaries can be approximately at least up to 1978. This paper therefore covers the period 1950-78.

\section{AVAILABILITY OF DATA}

It is useful first to note the data available for larger areas. Numbers of deaths by sex and cause are available for each standard region, conurbation, CB, London borough, and administrative county. ${ }^{6}$ From 1958 onwards, tables in the annual statistical reviews give standardised mortality ratios (SMRs) for each standard region and conurbation for 15 cancer sites, and also SMRs for the aggregates of all conurbations, all other urban areas by population size (100 000 and over, 50 000-99 999, and under 50000 ), and all RDs. ${ }^{78}$ In addition, numbers of deaths, rates, and SMRs for large areas were published for the four or five years around the census dates 1951, 1961, and
1971 in the decennial supplements on area mortality. ${ }^{1-3}$ For $1950-53$ and $1959-63$ the cancer sites covered were the stomach, bronchus and lung, breast, uterus, and leukaemia. More detailed analyses for 1969-73 included 20 sites or groupings of neoplasms, and the area coverage was improved by the division of each administrative county into separate aggregates of UDs and of RDs.

The only published data on mortality in small individual districts (except in the annual reports of Medical Officers of Health) are to be found in successive volumes of the Registrar General's statistical review. ${ }^{6}$ These provide annually total deaths by sex, a crude death rate for both sexes combined, and a comparison of this rate with the corresponding national rate after adjustment by an 'area comparability factor'. No data, published or unpublished, are routinely available for wards, civil parishes, or enumeration districts.

Unpublished tables of annual numbers of deaths since 1950 in each UD and RD are readily available from the Office of Population Censuses and Surveys (OPCS). Tables covering the years 1950-62 (known as ' $\mathrm{SD} 30$ ') give deaths by sex at all ages combined and from 1963 tables (known as 'SD 25s') give deaths in 10-year age-groups by sex. The causes covered ard shown in the Table. Before 1969, data were available for only a few major cancer sites, but there are 10 years' data (1969-78) for a wider range of sites eve though some important ancers have never bee $\overrightarrow{0}$ included. For the five years 1969-73 numbers of deaths in each district for a wide range of causes have been aggregated and SMRs calculated; these analyses are available from the OPCS. In addition, death records for each year from 1963 to 1973 are

Table Unpublished numbers of deaths available for urban and rural districts, 1950-78

\begin{tabular}{|c|c|c|c|}
\hline \multirow[b]{2}{*}{ Causes } & \multirow{2}{*}{$\begin{array}{l}\text { ICD codes, 6th } \\
7 \text { th revisions } \\
1950-67\end{array}$} & \multicolumn{2}{|c|}{ ICD codes, 8th revision } \\
\hline & & 1968 & $1969-78$ \\
\hline $\begin{array}{l}\text { All deseases other than neoplasms } \\
\text { Malignant neoplasms: }\end{array}$ & $\begin{array}{l}\text { Those on the } \\
\text { 'Abridged list' }\end{array}$ & \multicolumn{2}{|c|}{ Those on the augmented ' $B$ list' } \\
\hline Buccal cavity and pharynx & & - & $140-149$ \\
\hline Oesophagus & - & - & 150 \\
\hline Stomach & 151 & 151 & 151 \\
\hline Intestine and rectum & - & - & $152-154$ \\
\hline Larynx & - & - & 161 \\
\hline Trachea, bronchus, and lung & 162163 & 162 & 162 \\
\hline Breast & 170 & 174 & 174 \\
\hline Uterus & $171-174$ & $180-182$ & $180-182^{*}$ \\
\hline Prostate & - & - & 185 \\
\hline Leukaemia & 204 & 204-207 & 204-207 \\
\hline Other malignant neoplasms & $\begin{array}{l}\text { remainder of } \\
140-205\end{array}$ & $\begin{array}{l}\text { remainder of } \\
140-209\end{array}$ & $\begin{array}{l}\text { remainder of } \\
140-209\end{array}$ \\
\hline All malignant neoplasms (by addition) & $140-205$ & $140-209$ & $140-209$ \\
\hline Neoplasms of benign or unspecified nature & - & $210-239$ & $210-239$ \\
\hline All neoplasms (by addition) & - & $140-239$ & $140-239$ \\
\hline
\end{tabular}

* From 1974 cancers of the uterus are subdivided into those of the cervix and the remainder. 
held on computer at the OPCS; from these, tabulations of numbers of deaths by age, sex, cause, and local authority area can be produced.

Populations of UDs and RDs by sex and five-year age-groups are available from the appropriate county reports at each census, and may be applied to the periods 1949-53, 1959-63, and 1969-73.

\section{USES}

\section{(1) Descriptive studies}

There is considerable scope and need for basic descriptive studies, for at present we know little about variations in cancer mortality by district, and there may exist small zones of unusually high or low mortality of which we are ignorant. Mortality rates for aggregates of UDs or aggregates of RDs within an administrative county are not only of limited value but could in some instances prove misleading, for they are averages for districts which may be diverse and may have markedly different rates. For example, Davies $^{9}$ studied 10 towns in Nottinghamshire over the 18-year period 1958-75, and found that although their overall female stomach cancer SMR was 102 the ratios ranged from 68 to 137 .

An important first step in investigating a large area known to have high death rates is to ascertain the boundaries of the zone of raised mortality. For example, Stoke-on-Trent CB has long been known to have high stomach cancer death rates, and Davies (in preparation) has found that adjacent UDs to the north and west have similar rates in spite of differences in respect of some possible causative factors. Conversely it may be found that a CB has a raised death rate partly because of the arbitrary nature of its boundaries, which may exclude the town's affluent suburbs where death rates are low. For example, the raised stomach cancer SMR of 121 for men resident in Nottingham CB during 1969-73 can probably be partly accounted for by the fact that the two prosperous dormitory suburbs of Arnold and West Bridgford were separate UDs although effectively part of the same town, and the low death rates of their many residents in Social Classes I and II were not contributing to the rates for the CB.

Legon $^{10}$ examined the stomach cancer deaths in each RD in Wales during 1939-48 expressly to define more closely the known high mortality in north and west Wales, and Stocks ${ }^{11}$ examined death rates from digestive cancers during 1947-55 in 89 UDs and RDs covering five counties in North Wales and parts of Cheshire and Lancashire. Both authors were able to suggest hypotheses to account for the detailed mortality patterns they found. Mortality may also be studied within a CB; Freedman and Rubin $^{12}$ studied variations in lung cancer mortality in the 40 wards of Liverpool during 1970-74 (a rather short period for consideration of individual wards because of small numbers).

\section{(2) Hypothesis testing}

The types of study described so far are mainly exploratory: specific aetiological hypotheses might be suggested by the study results. Alternatively, studies may be designed from the outset to relate certain characteristics of a district or group of districts to mortality there. For example, Davies ${ }^{9}$ studied stomach cancer deaths in 10 Nottinghamshire UDs to see whether mortality was raised in those with high proportions of coal miners in their populations. Close attention to the effects of confounding factors is essential in such studies.

In Scotland Lloyd $^{\mathbf{1 3}}$ investigated lung cancer mortality during 1968-74 in a small town containing a steel foundry. He used census enumeration districts to subdivide the town into six zones, and found lung cancer mortality to be much higher in the zone downwind from the foundry. The feasibility of tracing excess mortality in a town to a certain occupation or industry by such methods may depend on local circumstances.

Grouping UDs or RDs can also facilitate the testing of specific aetiological hypotheses. It may be possible to select several small districts where the relevant variable is highly concentrated, whereas in CBs and administrative counties dilution usually occurs. This may be particularly true of occupations-for example, Warsop and Mansfield Woodhouse UDs in Nottinghamshire had over $40 \%$ of employed men in mining occupations in 1951, compared with only $20 \%$ in Nottinghamshire administrative county, ${ }^{14} \mathrm{a}$ feature utilised by Davies. ${ }^{9}$ Such specificity may be found for other variables also-for example, Fraser and Chilvers (in preparation) are studying gastric cancer mortality in 32 RDs grouped by the level of nitrate content in their water supplies. A study of areas with larger populations would have been of limited validity because of the complexity of water distribution networks.

Apart from such uses concerned with water supplies, type of employment, and industrial 'neighbourhood' effects, other variables could be studied in carefully selected groups of districts, including, for example, air or soil pollution, climatic and geological features, or type of land use.

\section{LIMITATIONS}

\section{(1) Small numbers of deaths}

A major problem when using mortality data for individual districts or smaller units is that numbers of observed or expected deaths are small and standard 
errors of SMRs are correspondingly large. For example, in their study of gastric cancer mortality Fraser and Chilvers (in preparation) found that the number of male deaths in each of 32 RDs during 1969-73 ranged from two to 55 .

This difficulty can be overcome in two ways. Firstly, deaths for many consecutive years can be aggregated if one can be reasonably sure that other relevant characteristics of the districts have remained constant. Davies ${ }^{9}$ used the 18-year period 1958-75 when studying Nottinghamshire towns. Secondly, areas with similar characteristics can be aggregated. Stocks ${ }^{11}$ studied mortality from cancers of numerous sites during 1947-55 in 89 districts in Wales, Cheshire, and Lancashire, and grouped contiguous districts into 17 divisions with similar geographical and environmental characteristics. Fraser and Chilvers (in preparation) classified RDs in terms of 'low', 'moderate', and 'moderately high' levels of water-borne nitrate; the deaths in each class of district were aggregated, and the test of differences in mortality levels was thus made more powerful.

\section{(2) Migration}

Studies of area variations in cancer mortality can be effective only if exposure to a carcinogen among the population of a given district gives rise to a subsequent excess of deaths in the same district. Such studies therefore assume that there has been little migration, and that most deceased persons have lived for substantial periods either at the addresses recorded on their death certificates or nearby in the same district.

Census reports for 1961 and 1971 provide information about migration by area. Although suitable data are not readily available for areas with populations of less than 50000 persons, consideration of two larger UDs in Nottinghamshire gives some indication of the scale of the problem. In Beeston and Stapleford UD 28\% of the 1971 census population had moved into the district from elsewhere in the five years preceding the census, and in Mansfield MB the corresponding figure was $24 \%^{15}{ }^{16}$; during the same period $19 \%$ of the population of each town had migrated outwards to other parts of Great Britain. These figures include persons of all ages, but for studies of variations in cancer mortality the older age groups are of most relevance. At ages 50 and over the proportions of persons who had moved into these towns in the same five years were $15 \%$ and $10 \%$ respectively, and the proportions of outward migrants were also $15 \%$ and $10 \%$.

Census data for 1961 indicate that the general level of migration was lower at that time, ${ }^{17} 18$ and suggest that in England and Wales as a whole some $75 \%$ of all persons aged 45 and over in 1961 had been resident in the same local authority district for at least $15 \bar{\Omega}$ years.

Two effects of migration would seem to be relevant here. Firstly, mortality rates of migrants moving for other than health reasons are lower than those of the general population, ${ }^{19}$ so that comparisons of areas T with very different proportions of inward or outward migrants could prove misleading. Secondly, in a district where exposure to a carcinogenic factor has occurred, some deaths of exposed persons will be lost $\stackrel{5}{\vec{D}}$ due to outward migration, and the population at risk will also be diluted by recent inward migrants; 흘 migration thus gives rise to a general dilution effect in $\frac{\bar{D}}{\widehat{D}}$ studies of cancer variations. Clearly local levels of $\stackrel{\varnothing}{\Omega}$ migration must be examined before districts are selected for study, and must be considered carefully when results are assessed.

\section{(3) Mortality versus morbidity data}

It is well recognised that mortality data are subject to some degree of inaccuracy arising from diagnostic $\stackrel{\curvearrowright}{\bigcirc}$ errors on death certificates. Nevertheless, as pointed $\dot{\omega}$ out by Adelstein, ${ }^{20}$ mortality statistics are recognised to be sufficiently accurate for many types of researco $\infty$ including studies of geographical differences, and their use is increasing.

In theory some of the problems inherent in the use of death data might be avoided by the use of data from cancer registries. For example, all cancer sites could be covered, and neoplasms not recorded ou. $\overrightarrow{0}$ death certificates as underlying causes of death would be included. The problems of delay between diagnosis and death and of migration due to the disease itself could be avoided. It is, however, known that registration is incomplete, ${ }^{2122}$ and that the degree of incompleteness varies in different hospital regions. ${ }^{23}$ Where registration is seriously incomplete the omissions are unlikely to be random, and could be related to area of residence. No registration statistics for small areas are routinely published, and some registries are not equipped to provide more detailed unpublished data. Moreover, since April 1974 registries have ceased to use the old local authority definitions.

For these reasons we consider that death records must at present continue to be the main source of data for the study of cancer variations in small administrative areas. However, we agree with Freedman and Rubin ${ }^{12}$ that whenever possible data from more than one source should be utilised, and some registries can provide material which can be used to check and augment the basic mortality data.

\section{(4) Problems with related variables}

Virtually all studies involve attempts to relate mortality patterns to other variables, either from the 
outset or in assessing results, but difficulties are commonly encountered owing to the unsatisfactory nature of the data available on the relevant variables. These difficulties may be minor in cases where detailed data at district level are available in census publications; examples are data on social class and occupations. The difficulties increase when data are available in adequate detail for counties and larger UDs, but are scanty at the level of RDs and smaller UDs; an example is information on migration.

Different and more serious problems arise when the relevant variables concern localities rather than individuals directly; examples are geological and climatic data. Such data may be available and published in detail, for example in the Wolfson Geochemical Atlas, ${ }^{24}$ but the problem is that they are not defined in terms of administrative areas, and may therefore not be compatible with the mortality data; difficult compromises may be involved in relating together the two sets of information. For example, an attempt to relate fertiliser usage to mortality from gastric cancer in the standard regions of England and Wales involved superimposing the map of hydrometric areas (for which the fertiliser data were available) on the map of standard regions (Fraser and Chilvers, in preparation).

Finally, the research worker may sometimes have to go out and collect the data he wishes to relate to his mortality patterns. For example, if he wished to relate deaths by district to air pollution or local dietary habits he would be unlikely to find data on these variables already available, although in isolated instances some local survey data might already exist or there might be background regional data.

\section{(5) Practical problems}

Various practical problems may add considerably to the work involved in this type of research, and may even preclude the study of some areas. Firstly, boundary changes must always be considered. These vary from small adjustments which do not materially affect populations at risk to the abolition or creation of districts by amalgamation. Another problem is that no population data are available for UDs and RDs after 1971, and if mortality data for subsequent years are used, the local populations must be estimated by extrapolation and may be liable to error. For the intercensal periods 1954-58 and 1964-68 interpolations must be made; 1966 sample census data on age-specific populations of small districts are not generally accurate, and better estimates can be made from 1961 and 1971 census data. ${ }^{9}$

There are two problems for those who wish to study mortality by wards or smaller divisions. One is that the OPCS cannot supply tabulations of deaths defined in terms of usual residence in geographical units smaller than UDs or RDs. To ascertain numbers of deaths by wards, the research worker must obtain copies of death entries for a whole town and himself determine which wards contained the addresses at death. Not only is it usually expensive to obtain the copies, but allocating addresses to wards is laborious and often difficult, especially without local knowledge of a town. The second problem is that population data are limited. Total populations of all wards and civil parishes by sex but not age have been published in county reports for 1951, 1961 and 1971 . The OPCS can provide unpublished sex- and agespecific populations of all wards and civil parishes in 1971 , but data are not available for all such areas in 1961. For 1951 only a limited range of civil parishes are covered by such data, and no further information is available on the populations of wards.

Finally, caution is needed if one wishes to use data for 1953-57, because during these years the OPCS changed the system of allocating deaths to district of 'usual residence' in respect of deaths occurring in certain types of hospital. This change produced anomalies in some local death rates. ${ }^{25}$

\section{Conclusions}

The data available for exploring mortality in small administrative areas are a largely unexploited resource; a far greater number of studies have been carried out on larger areas such as counties and county boroughs. Not only may the study of contiguous smaller districts provide insights into the validity of findings for counties and county boroughs, but little is known about mortality patterns in the districts themselves.

Apart from purely descriptive studies, we feel that district data can be used for generating and testing aetiological hypotheses. Where a variable of aetiological interest is highly concentrated in certain areas a geographical study may be an appropriate first step in testing a clue or hypothesis; it may indicate whether or not special studies are justified, and, if so, where effort should be concentrated. Compared with special studies using, for example, the case-control or longitudinal approach, geographical studies are relatively quick and economical in terms of both money and manpower, because they utilise routinely collected and readily available data.

Undoubtedly one of the reasons for the limited use made of these data is that considerable care and effort are involved in their handling, owing to the limitations and practical problems we have outlined, and to the need to allow for confounding variables. In particular the difficulty of small numbers may limit 
the scope of some studies, and over the period 1950-78 migration has become a confounding factor of increasing importance. However, in our opinion these limitations and problems in no way preclude the judicious use of the data.

From 1980 the OPCS are using the postcode area as the basic geographical unit for mortality data. Although postcodes may allow considerable flexibility in geographical mortality studies, there are likely to be many problems associated with their use. For example, not only are postcode boundaries liable to change but they also cut across local authority area boundaries. In addition, reliable population estimates will be available only at census dates. In the meantime it is unlikely that mortality data will be available after 1978 for urban and rural districts as formerly defined, and statistics covering the new county districts are of limited use for the types of study we have discussed.

Area mortality statistics are thus in a transitional stage, and in view of this and the increasing problem presented by migration, we feel that it is all the more important to make the maximum use of the 29 years' mortality data available on the old administrative districts of England and Wales.

Reprints from Dr. J. M. Davies, Division of Epidemiology, Block D, Institute of Cancer Research, Clifton Avenue, Sutton, Surrey SM2 5PX.

\section{References}

${ }^{1}$ Registrar General. Decennial Supplement, England and Wales 1951: Area Mortality. London: HMSO, 1958.

${ }^{2}$ Registrar General. Decennial Supplement, England and Wales 1961; Area Mortality Tables. London: HMSO, 1967.

${ }^{3}$ Office of Population Censuses and Surveys. Area Mortality 1969-73, Tables. Series DS No. 3 (microfiche). London: HMSO, 1979.

- Office of Population Censuses and Surveys. Area Mortality 1969-73. Series DS No. 4 (forthcoming). London: HMSO, 1980.

${ }^{5}$ Gardner MJ, Crawford MD, Morris JN. Patterns of mortality in middle and early old age in the county boroughs of England and Wales. Br J Prev Soc Med 1969; 23: 133-40.

${ }^{8}$ Registrar General. Statistical Review of England and Wales, 1950 et seq, Part I Tables, Medical. London: HMSO, 1952 et seq.
${ }^{7}$ Registrar General. Statistical Review of England and $\overline{\mathrm{D}}$. Wales, 1958 et seq, Part III Commentary. London: HMSO, 1960 et seq.

${ }^{8}$ Registrar General. Statistical Review of England and Wales, 1965 et seq, Part I Tables, Medical, appendices. London: HMSO, 1967 et seq.

${ }^{9}$ Davies JM. Stomach cancer mortality in Worksop and other Nottinghamshire mining towns. Br J Cancer 1980; 41: 438-45.

${ }^{10}$ Legon CD. A note of geographical variations in cancer $\cong$ mortality, with special reference to gastric cancer in Wales. Br J Cancer 1951; 5: 175-9.

${ }^{11}$ Stocks P. Annual Report of the British Empire Cancer Campaign, 1957, Supplement to Part II. London: British Empire Cancer Campaign, 1958.

${ }^{12}$ Freedman LS, Rubin SG. Limitations of mortality data as a guide to comparative lung cancer incidence within an urban area. Public Health 1979; 93: 111-6.

${ }^{13}$ Lloyd OL. Respiratory cancer clustering associated with localised industrial air pollution. Lancet 1978; 1: के 318-20.

${ }^{14}$ General Register Office. Census 1951 England and Wales: Occupation Tables. London: HMSO, 1956: 267, 272, 408, 412.

${ }^{15}$ Office of Population Censuses and Surveys. Census 1971 England and Wales: County Report Nottinghamshire Part I. London: HMSO, 1973: 12 et seq.

${ }^{16}$ Office of Population Censuses and Surveys. Census $1971 \omega$ England and Wales: Migration Regional Reports (10\$ sample) East Midlands Region Part I. London: HMS $Q$, 1975: 57, 59.

${ }^{17}$ General Register Office Census 1961 England an Wales: Migration Tables. London: HMSO, 1966: Tabl@ $2,4,9$.

${ }^{18}$ Office of Population Censuses and Surveys and Genera Register Office. Census 1971 Great Britain: Migratiog Tables Part IV (10\% sample). London: HMSO, 197 Tables 28A, 28B.

${ }^{19}$ Fox AJ. Prospects for measuring changes in differentia mortality. Proceedings of World Health Organisation and United Nations meeting on Socioeconomic Determinants and Consequences of Mortality. Mexico. City: June 1979, (in press).

${ }^{20}$ Adelstein AM. Death certification and epidemiological research. Br Med J 1978; ii: 1229-30.

${ }^{21}$ Alderson M. In: Maunder FW, ed. Reviews of United Kingdom Statistical Sources, Volume II. London: Heinemann Educational Books, 1974.

${ }^{22}$ Freedman LS. Variations in the level of reporting by hospitals to a regional cancer registry. Br J Cancer 1978; 37: $861-5$

${ }^{23}$ Office of Population Censuses and Surveys. Cancer Incidence in Great Britain 1963-66. Studies on Medical and Population Subjects No. 24. London: HMSO, 1972.

${ }^{24}$ Webb JS, Thornton I, Thompson M, Howarth RJ, Lowenstein PL. Wolfson Geochemical Atlas of England and Wales. Oxford: Oxford University Press, 1978.

${ }^{25}$ Hewitt D. Vagaries of local mortality rates under the 1953-54 rules for transfer of deaths. Br J Prev Soc Med 1956; 11: 45-9. 